\title{
Article \\ Thermal and Principal Ablation Properties of Carbon-Fibre-Reinforced Polymers with Out-of-Plane Fibre Orientation
}

\author{
Sebastian Eibl *(D) and Thomas J. Schuster (D) \\ Bundeswehr Research Institute for Materials, Fuels and Lubricants, Institutsweg 1, D-85435 Erding, Germany; \\ thomasschuster@bundeswehr.org \\ * Correspondence: SebastianEibl@bundeswehr.org
}

\begin{abstract}
This work characterises thermal properties of a typical epoxy-based carbon-fibre-reinforced polymer used in aircraft construction, but with an out-of-plane fibre orientation, and assesses its potential as a structural ablative material. Samples of the commercially available Hexply ${ }^{\circledR}$ 8552/IM7 are prepared with out-of-plane angles up to $90^{\circ}$, with a focus on $0^{\circ}$ to $15^{\circ}$, enhancing thermal conductivity through the thickness of the panel. Ablation processes are simulated by a hot-air blower at $580{ }^{\circ} \mathrm{C}$, and examined in detail by ultrasonic testing and microfocused computed X-ray tomography afterwards. Matrix degradation is characterised by infrared spectroscopy and mass loss. To assess structural properties, tensile, compression, and bending tests are performed. The results show a loss in mechanical performance with an increasing fibre angle, which may be negligible for angles lower than $\sim 5^{\circ}$ in the initial state. Composite material with an out-of-plane fibre orientation is deeply penetrated concerning matrix degradation by thermal loading, but it is held together by the fibres fixed in the intact matrix underneath. This type of material shows a high potential for structural components in single-use, high-temperature, ablative applications with a focus on saving weight.
\end{abstract}

Citation: Eibl, S.; Schuster, T.J. Thermal and Principal Ablation Properties of Carbon-FibreReinforced Polymers with Out-of-Plane Fibre Orientation. C 2021, 7, 64. https://doi.org/ $10.3390 /$ c7030064

Academic Editors: Ulf Breuer, Lazaros Tzounis and Martin Gurka

Received: 16 July 2021

Accepted: 16 August 2021

Published: 21 August 2021

Publisher's Note: MDPI stays neutral with regard to jurisdictional claims in published maps and institutional affiliations.

\section{Introduction}

Carbon-fibre-reinforced polymer matrix composites (CFRP) are widely used for aerospace, ballistic, and engineering components, etc., because of their low specific weight and excellent mechanical characteristics [1]. As polymers are usually susceptible to thermal damage, many studies deal with their temperature behaviour and the use of flame retardants. For flame retardants for epoxy-based composites [2,3], new developments are typically halogen-free [4-7] and/or nano-scaled [8]. In order to protect CFRP structures from elevated temperatures in, for example, hypersonic applications, ablation processes $[9,10]$ are typically exploited in aeronautical and aerospace construction [11-14]. In an ablation process, high energy inputs are dissipated by the material through endothermic processes, in which the material itself is usually degraded or consumed $[15,16]$. Depending on the application area, there are different materials for ablation structures and different test methods, such as powered plasma jets, oxy-acetylene torch heaters, rocket exhausts, radiant heating lamps, etc. [17]. Significant properties of an ablative material are density, thermal conductivity, and specific heat capacity, influencing the heat of ablation as well as the heat and mass transfer rate $[17,18]$. However, additional layers and additives usually result in higher weights. There have already been investigations to enhance the thermal conductivity of lightweight composites, which could be achieved, for example, by conductive fillers such as carbon black and/or carbon nanotubes [19-21]. Park et al. additionally investigated the thermal behaviour of these materials and reported better ablation properties [22]. A simple approach to avoid fillers with their accompanying disadvantages (e.g., higher resin viscosity $[23,24]$ ) is to use the carbon fibres themselves to enhance the thermal conductivity and ablation behaviour of CFRP, as their thermal conductivity is much higher 
than that of the polymeric matrix. Additionally, carbon fibres resist higher temperatures compared to the polymeric matrix, and during the combustion of CFRP they typically act as barriers concerning heat and mass transfer [25]. A new approach within this work is to change the direction of the fibres out-of-plane to improve thermal conductivity through the thickness of the composite material and to enhance its ablation properties. A fibre orientation with low out-of-plane angles may still provide a protective barrier effect. In addition, fibres at the surface are not as easily ablated as in layered CFRP samples with regular fibre orientation, because these fibres are still locked into deeper positions inside the intact material during ablation. By this, a longer duration is achieved to withstand high temperatures under ablative conditions. However, mechanical properties are supposed to suffer from out-of-plane fibre orientation. Therefore, the mechanical performance of composites with an out-of-plane fibre orientation is analysed in detail before and after the ablation experiments. As this performance is expected to be highly sensitive on fibre orientation and may not be excessively reduced, this study focusses on angles lower than $15^{\circ}$, with prospects up to $90^{\circ}$.

After the ablation experiments, non-destructive evaluation techniques are applied such as ultrasonic testing, microfocused computed X-ray tomography $(\mu \mathrm{CT})$, and infrared spectroscopy (ATR-FTIR). Infrared spectroscopy provides especially deep insight into degradation processes of the polymer matrix when it is not extensively decomposed.

Samples of the epoxy-based CFRP system Hexply ${ }^{\circledR}$ 8552/IM7 with an out-of-plane fibre orientation used for this work have already been investigated for their reaction-tofire properties by cone calorimetry [26]. For the presented study, ablation processes are simulated by a hot-air blower at $580{ }^{\circ} \mathrm{C}$. Corresponding tests according to ASTM E285 [27] using an oxy-propane flame are additionally carried out.

The aim of this work is to gain deep insight into degradation processes of CFRP with an out-of-plane fibre orientation at a one-sided thermal load and developing temperatures beyond the decomposition temperature of the polymer matrix. For the first time, their potential is assessed for using them under ablating conditions in structural components with the advantage of not needing additional ablative additives or ablation layers [28].

\section{Material}

The investigated commercially available CFRP system Hexply ${ }^{\circledR}$ 8552/IM7 from Hexcel Composites $\mathrm{GmbH}$ consists of an epoxy resin $(\sim 29 \mathrm{wt} . \%)$ and is toughened with a polyethersulfone $(\sim 6 \mathrm{wt} . \%)$ [29]. Its maximum operational temperature is $121^{\circ} \mathrm{C}$ [30]. A total of 960 prepreg layers are unidirectionally stacked and cured in an autoclave process according to the manufacturer's recommended conditions [30]. No distinguishable fibre layers exist after curing, as carbon fibres are nearly homogeneously distributed throughout the resulting CFRP cube [25]. Test samples $2 \mathrm{~mm}$ thick with an out-of-plane fibre orientation are cut out of the CFRP cube in different angles using a water-cooled diamond wire saw, as schematically shown in Figure 1, creating fibre angles between $0^{\circ}$ and $90^{\circ}$ with respect to the panel surface. All panels contain identical ratios of fibre-matrix content as well as fibre-matrix areas at the surface. Each sample is visually inspected for surface damages and ultrasonically tested to ensure that it is free of voids and delaminations. Samples are subsequently dried in an oven at $70{ }^{\circ} \mathrm{C}$ for a minimum of a week. 

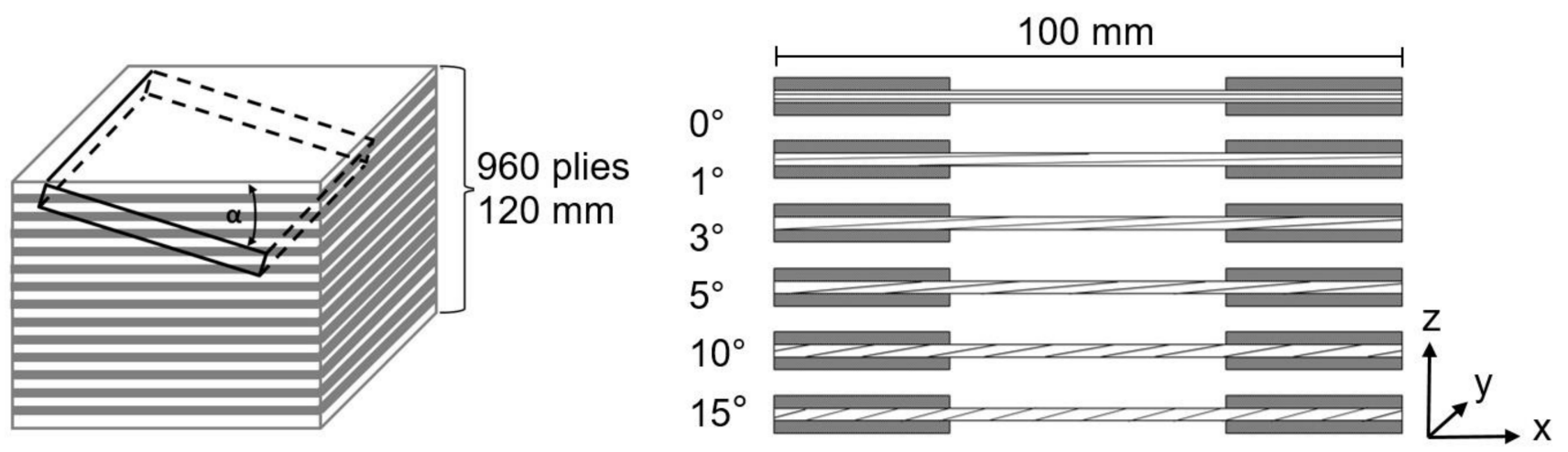

Figure 1. Schematic representation of a cube consisting of 960 plies used to cut specimens with out-of-plane fibre angles with respect to the panel surface. Schematic cross-sections of tensile test specimens are shown on the right side.

\section{Experimental}

Thermal loading/ablation tests are predominantly performed using a $\sim 5 \mathrm{~kW}$ heat gun ("Lufterhitzer 5000", Leister Type 8D4) using compressed air ( 4 bar) with a nozzle diameter of $8 \mathrm{~mm}$ and an air temperature at the nozzle of $580 \pm 5^{\circ} \mathrm{C}$. It is adjusted with a distance of $5 \mathrm{~mm}$ to the vertically aligned samples $\left(20 \times 10 \times 2 \mathrm{~mm}^{3}\right)$. Samples are clamped in a specially designed metal holder avoiding thermal conduction into the support by four pins. Temperatures are recorded at the free back side of the samples at three positions (see Figure 2) with attached type $\mathrm{K}$ thermocouples. Preceding tests using a propane flame for ablation experiments are carried out with a commercial welding gun at an oxygen flow of $374 \mathrm{~mL} / \mathrm{min}$ and a propane flow of $122 \mathrm{~mL} / \mathrm{min}$ resulting in a stable flame with an inner cone of $5 \mathrm{~mm}$. For comparison reasons, horizontally aligned samples are irradiated at $60 \mathrm{~kW} / \mathrm{m}^{2}$ at a distance of $25 \mathrm{~mm}$ from an electrical heater of a cone calorimeter [31] for various durations up to time to ignition.

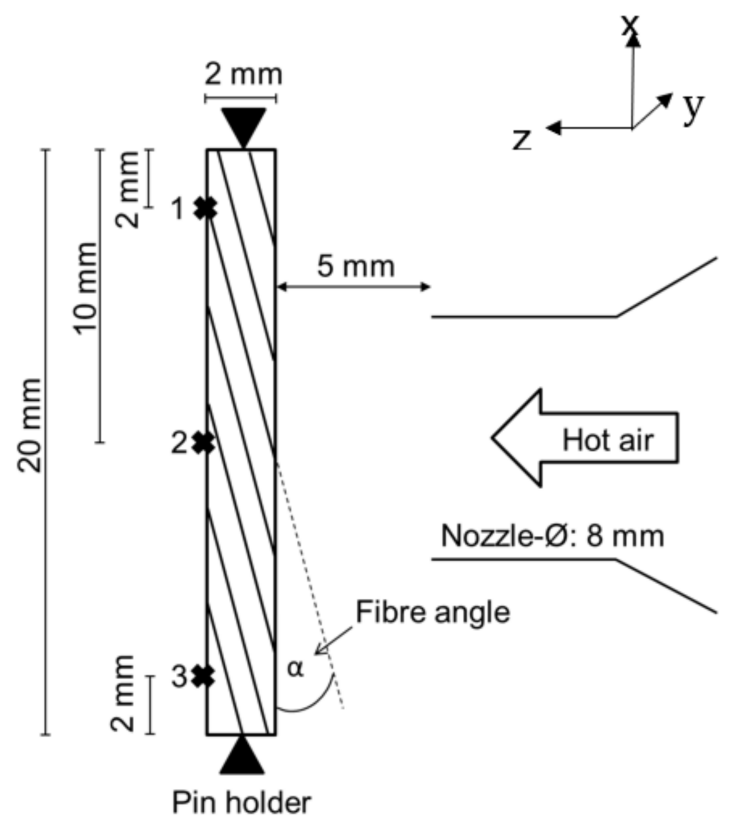

Figure 2. Schematic sectional view of the ablation experiment with marked positions for the attached thermocouples and the subsequent FTIR analysis.

Tensile tests are performed according to DIN EN ISO 527-5 [32] using a universal testing machine. Divergent for this standard specification, sample length is reduced to $100 \mathrm{~mm}$ due to the size of the CFRP cube. The free sample length is, therefore, $44 \mathrm{~mm}$. Because of these reductions, the sample width is adjusted to $10 \mathrm{~mm}$ and thickness to 
$2 \mathrm{~mm}$. Short beam shear and compressive strength are tested according to DIN EN ISO 14126 [33] and DIN EN ISO 2563 [34], respectively, also using a universal testing machine by ZwickRoell.

Thermogravimetric analysis (TGA) is performed in air using a STA 449 (Netzsch, Selb, Germany) with a heating rate of $10 \mathrm{~K} / \mathrm{min}$. Thermal conductivity is calculated as a product of temperature conductivity, density and specific heat capacity, all measured at $15^{\circ} \mathrm{C}$. Measurement of temperature conductivity is performed by a Laser Flash Analysis (LFA) according to DIN EN ISO 22007-4 [35] using a LFA 427 (Netzsch). Heat capacity is measured according to DIN 53765 F [36] on a DSC Q2000 (TA Instruments, New Castle, DE, USA) and density is determined gravimetrically according to DIN EN ISO 845 [37]. Thermal expansion is measured by thermomechanical analysis (TMA), which is carried out with a Netzsch TMA 402 Hyperion system with a heating rate of $3 \mathrm{~K} / \mathrm{min}$.

Changes in the composition of the polymer matrix due to the thermal load are analysed by micro Attenuated Total Reflection Fourier Transform Infrared Spectroscopy ( $\mu$-ATRFTIR). Spectra are recorded with a Bruker Tensor 27 spectrometer and a Harrick ATR cell equipped with a silicon crystal (diameter: $0.1 \mathrm{~mm}$ ) on the specimens' back side at three positions given in Figure 2. Three spectra are recorded for every spot and received band intensities are averaged. Data analysis was performed as described elsewhere [26].

Microfocused computed X-ray tomography $(\mu \mathrm{CT})$ is performed using a General Electric V-TOME XL300 system with a $300 \mathrm{kV}$ microfocus X-ray source, with a voxel size of $14 \mu \mathrm{m}$.

Scanning electron microscopy (SEM) images are recorded at $1.0 \mathrm{kV}$ with a Zeiss Ultra Plus microscope. Ultrasonic scanning is performed according to EN 45000 with a USPC 3010-HFUS 2000 by DR. HILLGER equipped with a Panametrics $20 \mathrm{MHz}$ sensor head with a resolution of $2 \mu \mathrm{m}$.

\section{Results and Discussion}

\subsection{Basic Characterisation of Mechanical and Thermal Properties}

The results of the tensile, compression and short beam shear tests for CFRP material with an out-of-plane fibre orientation are shown in Figure 3. As expected, mechanical performance typically decreases with an increasing fibre angle. As for increasing fibre angles, mechanical load is more and more borne by the weaker matrix compared to the fibres. Additionally, failure modes for the various mechanical testing methods change for samples with an out-of-plane fibre orientation. In a tensile test of samples with fibres orientated in load direction $\left(0^{\circ}\right)$, all fibres reach from one clamp to the other, and strength is dominated by fibre properties. For increasing out-of-plane angles, fibres clamped at one side may not reach the other clamp (see Figure 1). Then, mechanical performance is dominated by the matrix and/or fibre/matrix interface properties, as fracture occurs in an interlaminar manner (see Figure 4). Similarly, in short beam shear tests, the failure mode changes from interlaminar for samples with an out-of-plane fibre angle of $0^{\circ}$ to cracking along the fibres for samples with a $90^{\circ}$ fibre angle. Therefore, fracture areas change with fibre angle and test results are influenced by sample dimensions and experimental setup. Nevertheless, mechanical strength is still calculated on basis of the initial cross-sectional area of the samples for comparison reasons, keeping in mind the mechanistic changes. A discussion of this topic based on laminate theory [38] is beyond the scope of this work, as it focusses on thermal and ablative properties of CFRP material with an out-of-plane fibre orientation. When this material is used for ablative components, a loss in mechanical performance has to be taken into account, which may be, however, tolerable for out-ofplane fibre angels lower than $\sim 5^{\circ}$. For example, a fibre angle of $3^{\circ}$ leads to a reduction of $1 \%$ for the calculated short beam shear strength (SBSS) using the fixed cross-sections and $24 \%$ for tensile and compressive strength compared to the $0^{\circ}$ fibre orientation. As expected, the decrease in SBSS is less sensitive to the fibre angle, as the sample dimensions and the experimental setup show less influence on the type of fracture compared to tensile strength. For an out-of-plane fibre orientation of $90^{\circ}$, compressive strength is less reduced 
compared to tensile and short beam shear strength, as this strength type is most influenced by matrix properties [39]. Without the influence of the dimensions of the test specimens on mechanical properties, the loss of mechanical performance of a composite component might be less pronounced and compensated with slightly thicker material.

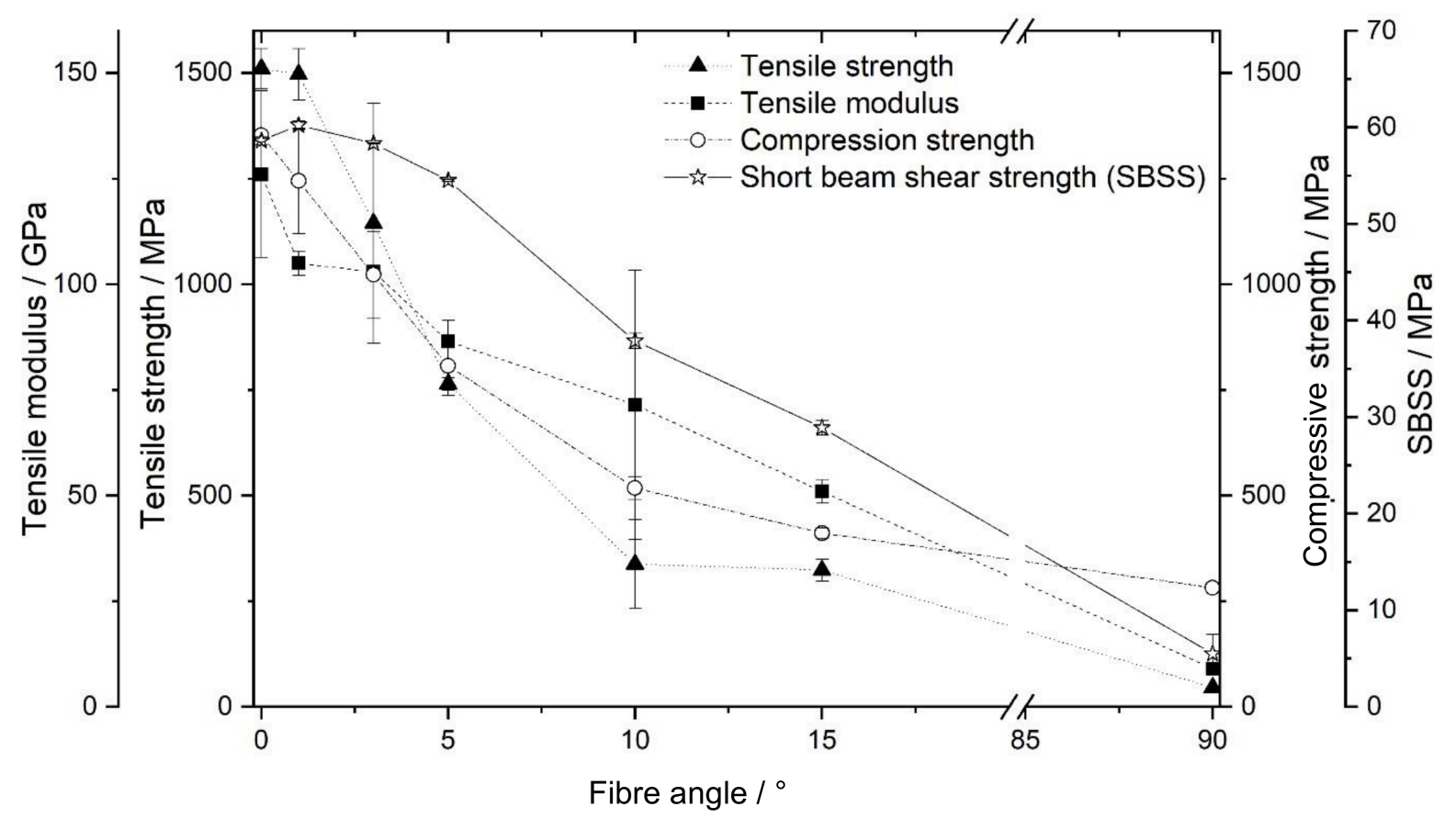

Figure 3. Mechanical performance of CFRP samples with an out-of-plane fibre orientation. (Given strengths are calculated for the initial cross-sections of the samples and not the area of failure (see text).)
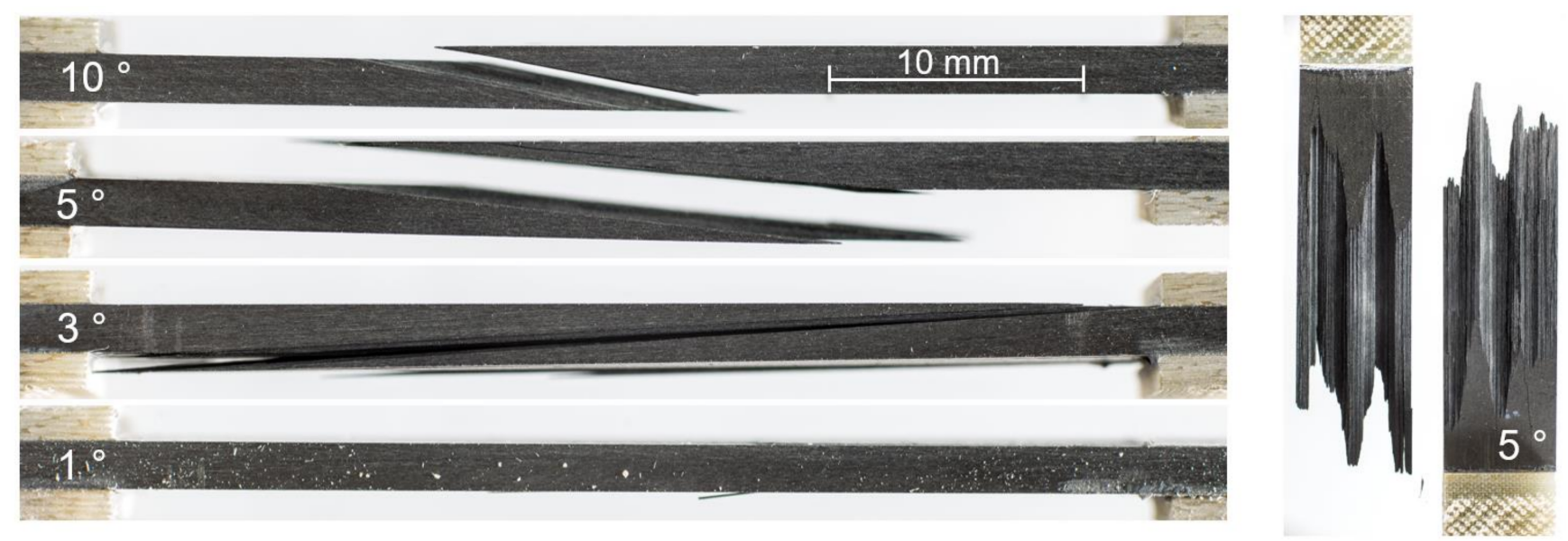

Figure 4. Thermally not treated samples with out-of-plane fibre orientation after tensile testing.

An important property for ablative materials is their thermal conductivity. Thermal energy is mainly conducted by the carbon fibres, as they show higher thermal conductivity than the surrounding polymers. Therefore, the through-thickness thermal conductivity of the composite rises significantly with an increasing fibre angle, as shown in Figure 5. The thermal conductivity of composites with a $90^{\circ}$ fibre angle reaches the value of the used carbon fibres, which is given as $5.40 \mathrm{~W} / \mathrm{m} \cdot \mathrm{K}$ [40]. The angle dependency of the thermal conductivity (TC) may also be simulated by Equation (1), with $T C_{0}$, being the thermal 
conductivity through the thickness of samples with an out-of-plane angle $(\alpha)$ of $0^{\circ}$ and $T C_{90^{\circ}}$ for $90^{\circ}$, as described by Hasselman et al. [41]:

$$
T C=T C_{0^{\circ}} \cdot \cos ^{2}(\alpha)+T C_{90^{\circ}} \cdot \sin ^{2}(\alpha)
$$

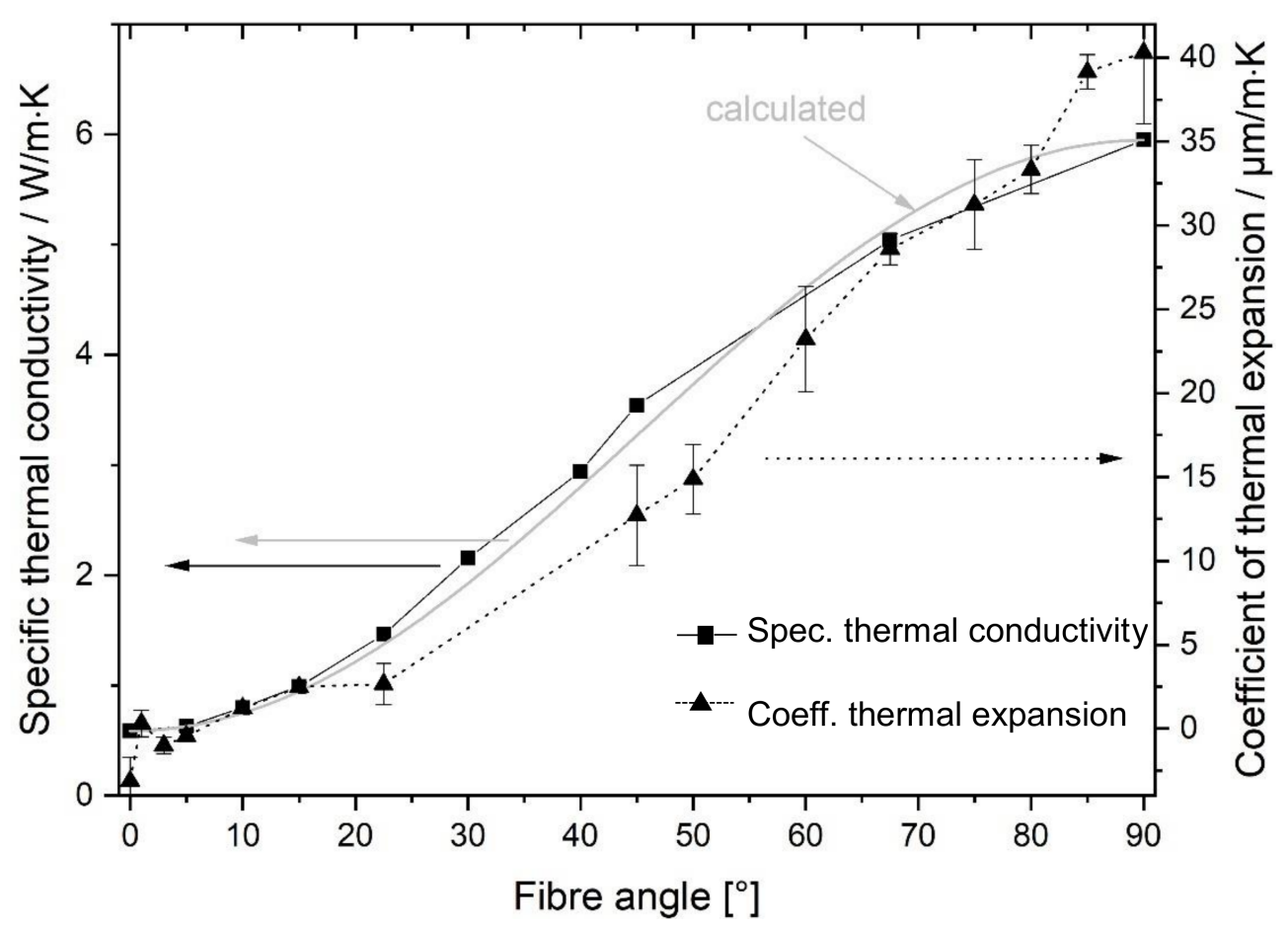

Figure 5. Thermal conductivity at $15^{\circ} \mathrm{C}$, additionally calculated according to Equation (1) and thermal expansion coefficient of CFRP with given out-of-plane fibre orientation.

The data shown in Figure 5 fit well with this simulation. The thermal expansion coefficient (Figure 5) is negative for an out-of-plane angle of $0^{\circ}$, which is typical for carbon fibres. At an out-of-plane fibre angle of $90^{\circ}, 40 \mu \mathrm{m} / \mathrm{m} \cdot \mathrm{K}$ is measured, typical for the pure resin. For out-of-plane fibre angles in between, the thermal expansion coefficient shows a similar trend as the thermal conductivity. Further details of the thermal expansion and conductivity of 8552/IM7 with out-of-plane fibre angle are reported in [26].

\subsection{Ablation Experiments}

In principle, ablation properties can be tested by ASTM E285 [27]. Flat samples of ablative materials are treated with a flame of an oxyacetylene burner. Preceding experiments similar to ASTM E285 using an oxygen-propane flame turned out to be not suitable to systematically investigate ablation properties of the used epoxy-based CFRP. For the chosen experimental conditions with distances of 5 to $50 \mathrm{~mm}$ between welding gun and specimen, and test durations of 4 to $10 \mathrm{~s}$, the material is heated up very rapidly and ignites. Figure 6 shows selected back side temperatures during the application of a propane flame on samples with no out-of-plane fibre orientation. After only $4 \mathrm{~s}$ of the flame impinging the sample from a distance of $5 \mathrm{~mm}$, a rapid heat up on the samples back side is observed. This steep temperature rise continues after removing the pilot flame due to sustaining oxidative decomposition of the sample and persisting heat conduction to the back side. Maximum back side temperatures are reached in the range of $300^{\circ} \mathrm{C}$. For this experimental setup, it was not possible to reliably measure front side temperatures. However, they are assumed to be much higher than the necessary temperature for ignition of the material at 350 to $400{ }^{\circ} \mathrm{C}$ [25]. When applying the pilot flame for $10 \mathrm{~s}$ from a distance of $10 \mathrm{~mm}$, the temperatures on the back side indicate an extensive decomposition and combustion of the matrix through the thickness of the specimen, as temperatures close to $600{ }^{\circ} \mathrm{C}$ are 
reached and a sustaining flame is observed over $5 \mathrm{~s}$ after removing the pilot flame. The observed mass loss of $25 \%$ is typical for a combustion of 8552 /IM7 samples tested by cone calorimetry [25]. Even for a larger distance of $50 \mathrm{~mm}$ between welding gun and specimen, the reached high back side temperatures indicate conditions of a rapid decomposition of the matrix in the CFRP material. For this experimental condition, the back side heats up a little slower and influences by formed delaminations are observed by an intermediate drop in the heating rate [42]. However, none of the $2 \mathrm{~mm}$ thick samples retain a significant residual strength after the conducted experiments.

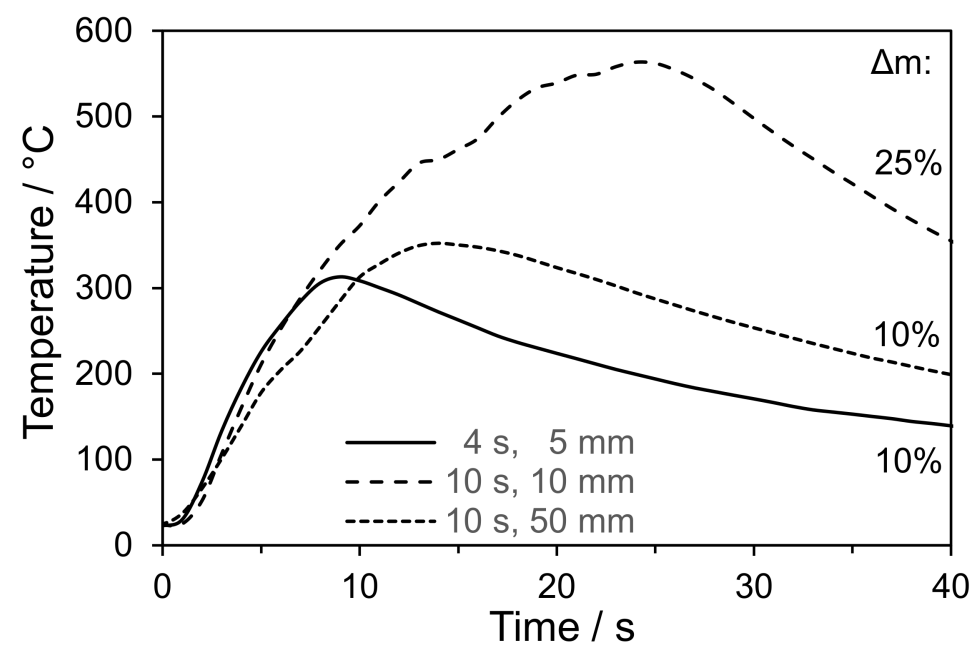

Figure 6. Temperature on the back side of samples with $0^{\circ}$ fibre angle, during application of a propane flame for the given duration and distance between sample and welding gun, as well as corresponding mass loss $(\Delta \mathrm{m})$ after the experiment.

This type of experiment is typically used to simulate ablative environments in rocket motors more than during aerodynamic heating [27]. Therefore, ablation properties were decided to be characterised by experiments using a heat-gut with $580^{\circ} \mathrm{C}$ hot air. Carbon fibres withstand this temperature, as for their decomposition in air, typically a minimum threshold temperature of $\sim 650^{\circ} \mathrm{C}$ is necessary [43]. The polymeric components' epoxy resin and polyethersulfone degrade below $580{ }^{\circ} \mathrm{C}$, with the epoxy resin being less thermally reistant than the polyethersulfone, as shown in the thermogravimetric analysis in Figure 7. However, no ignition of the samples is observed throughout the tests and test durations are long enough to differentiate the influence by out-of-plane fibre orientation.

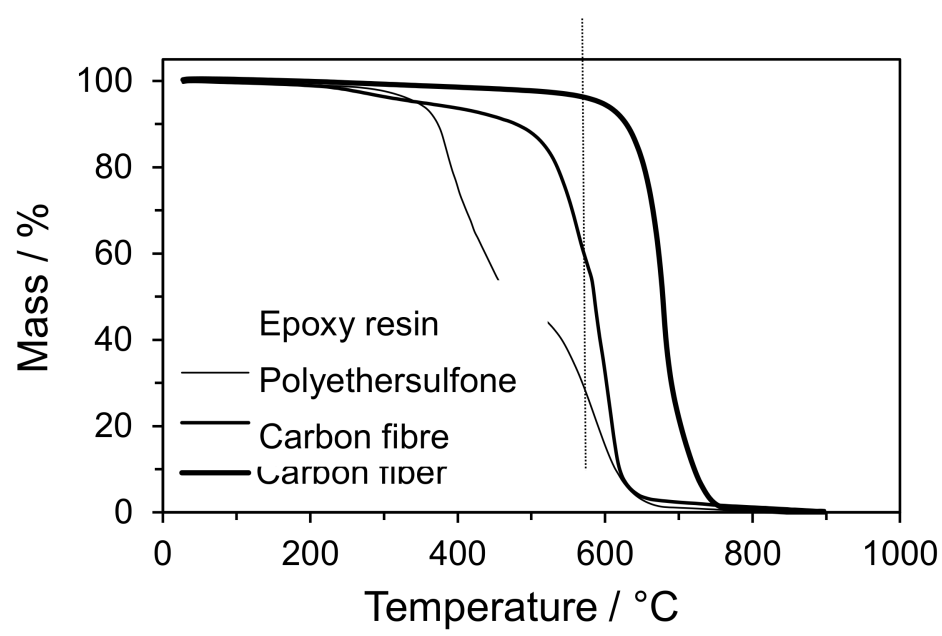

Figure 7. Thermogravimetric analysis of the separated components of the used CFRP. (Air temperature of $580{ }^{\circ} \mathrm{C}$ for ablation experiments is indicated.) 
The recorded temperature rises on the back side of the samples with an out-of-plane fibre orientation are given in Figures 8 and 9, summarising maximum temperatures averaged for all conducted experiments with hot air after 60,300 and $600 \mathrm{~s}$. An equilibrium temperature is reached after $\sim 25 \mathrm{~s}$. For an out-of-plane fibre angle of $0^{\circ}$, a homogeneous temperature distribution $\left(\sim 240^{\circ} \mathrm{C}\right)$ is observed at the samples' back side, as temperature curves at position 1 and 3 are nearly identical. For higher angles beginning from $3^{\circ}$, equilibrium back side temperatures are, in general, higher due to the increased thermal conductivity of the samples (see Figure 5) and especially higher at position 1 compared to position 3. For an angle of $15^{\circ}$, temperature difference between position 1 and 3 on the back side is $\sim 70{ }^{\circ} \mathrm{C}$ (see also Figure 9). The preferred heat conduction along the fibres leads to an increasing temperature difference between position 1 and 3 . At position 3 , the reached temperatures are lower. As for high out-of-plane fibre angles, no fibres with a fibre end at the thermocouple position on the back side reached the front side. Such fibres only reached the lower edge of the sample (see inserted schemes in Figures 8 and 9). At position 1 and 2 , these effects are less pronounced, and occurring temperatures better represent those of a large component. The observed temperature differences in the equilibrium state of the experiment prove that more heat is conducted to the samples' back side for increasing out-of-plane angles.

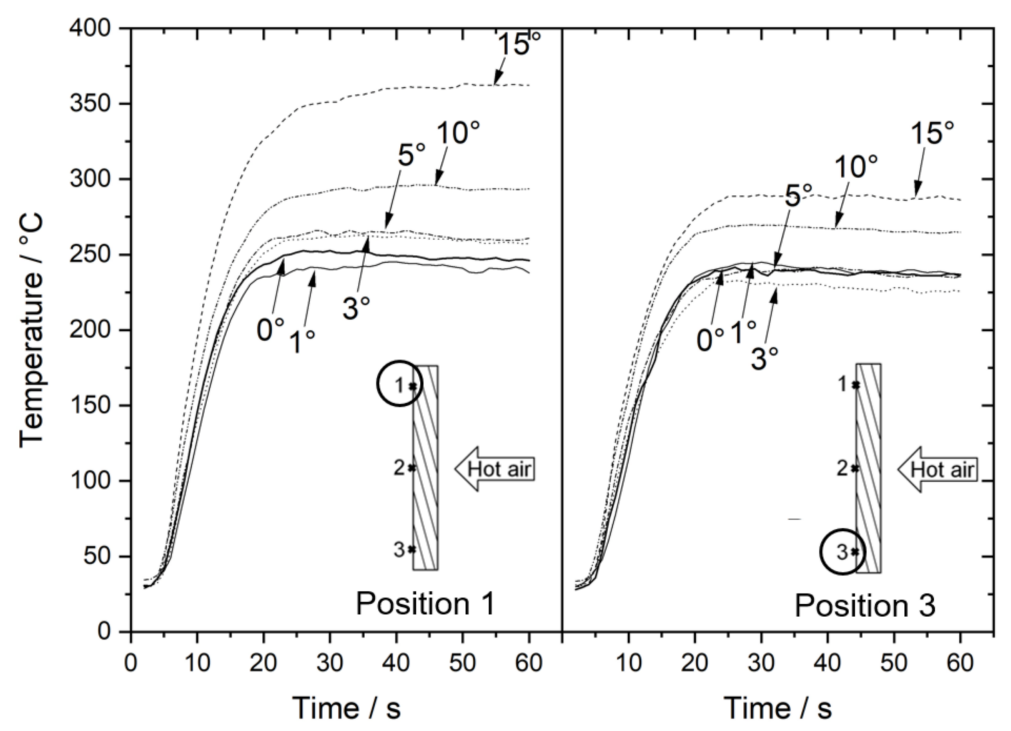

Figure 8. Temperature profiles on the back side of samples with different fibre angles during hot-air treatment: measured at position 1 (left); measured at position 3 (right).

The recorded equilibrium back side temperatures from 280 to $390{ }^{\circ} \mathrm{C}$ in Figure 9 are in a range of rapid matrix degradation of the 8552/IM7 composite [44]. High temperature gradients occur inside the samples with an assumed front side temperature close to the temperature of the impinging hot air. Therefore, a pronounced mass loss due to matrix decomposition is observed after the ablation experiment. However, the reached temperatures on the back side are lower compared to the impinging propane flame, and no ignition of the samples is observed. In irradiation experiments, temperatures of $\sim 400{ }^{\circ} \mathrm{C}$ at the the front side were observed to be sufficient for ignition [25,44]. As temperatures are higher in the ablation experiment and no ignition occurs, it can be concluded that the rapid flow of hot air dilutes and removes formed pyrolysis gases, and critical concentrations therefore necessary for ignition are not achieved. 


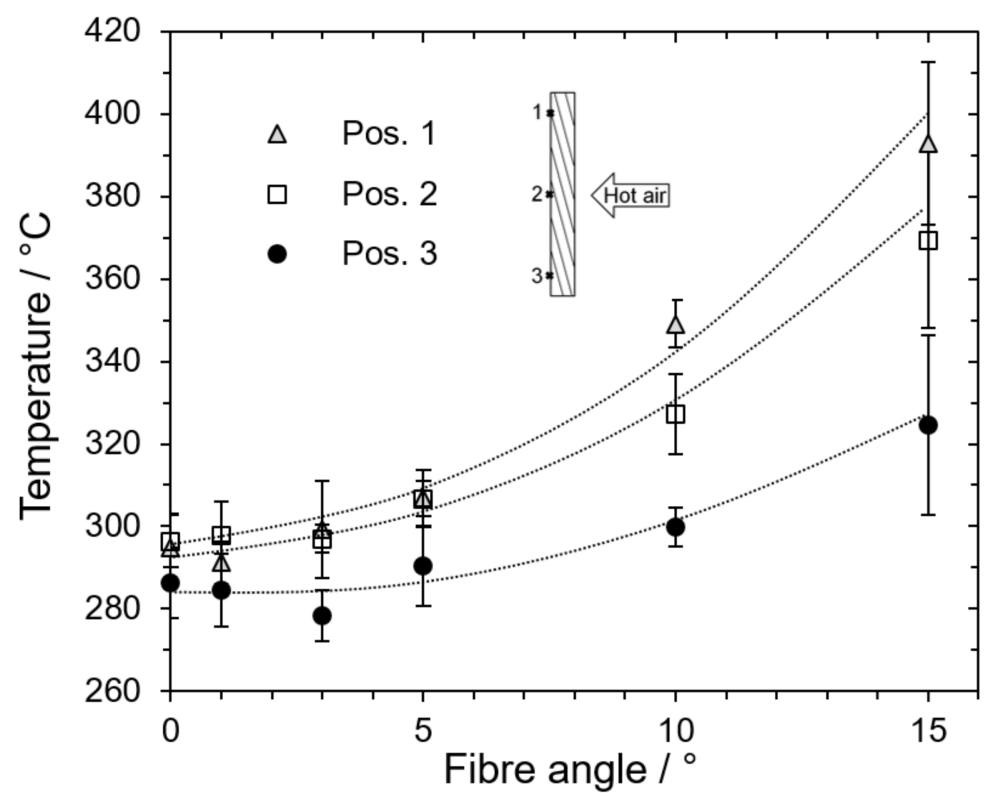

Figure 9. Reached equilibrium back side temperatures after ca. $30 \mathrm{~s}$ (see Figure 8).

\subsection{Material Characterisation after Thermal Impact}

To measure the effect of different fibre angles on thermal damage, first mass loss due to the decomposition of the polymer matrix is determined. The results are shown in Figure 10. Mass loss increases with time of thermal load (60,300 and $600 \mathrm{~s})$ but is more pronounced with an increasing fibre angle. As after ca. $25 \mathrm{~s}$ equilibrium back side temperatures are reached (see Figure 8), the increasing thermal decomposition of the resin matrix, in general, occurs with an increasing duration of thermal loading at certain temperature levels. However, when comparing samples with $0^{\circ}$ and $15^{\circ}$ out-of-plane angles, mass loss is 2 to 3 times higher for samples with $15^{\circ}$. According to the higher reached temperatures through the thickness of the panels with high out-of-plane fibre angles, extended matrix decomposition is responsible for the observed mass loss.

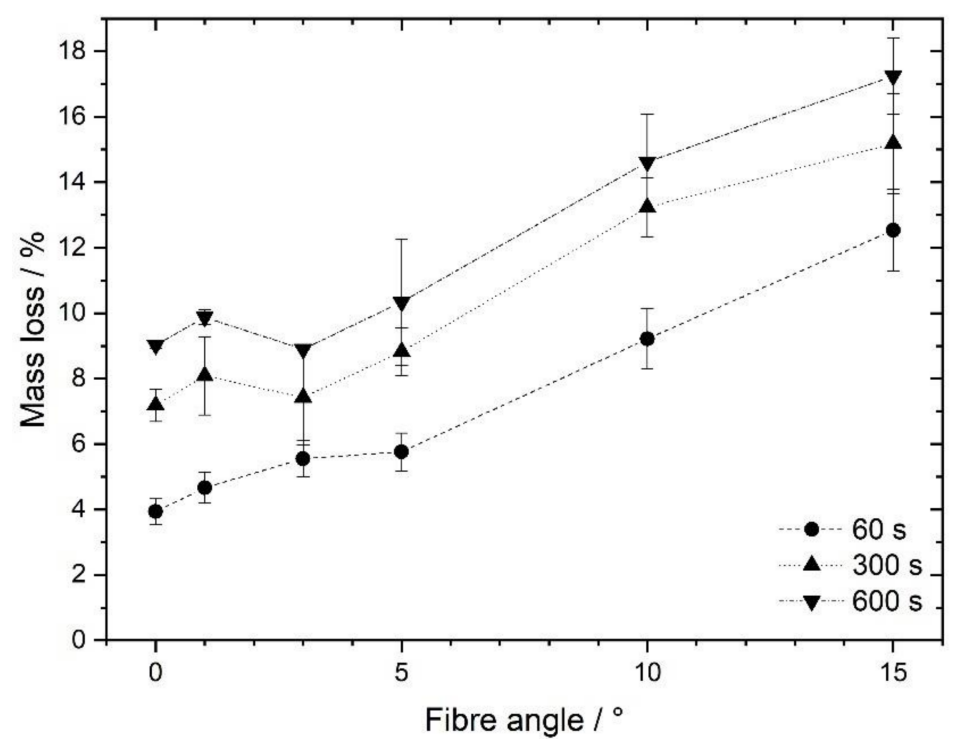

Figure 10. Mass loss of CFRP with an out-of-plane fibre orientation after different durations of hot-air treatment.

Increasing matrix decomposition with increasing out-of-plane fibre angles is also indicated by ultrasonic C-scans (Figure 11) and $\mu \mathrm{CT}$ cross-section images (Figure 12). 


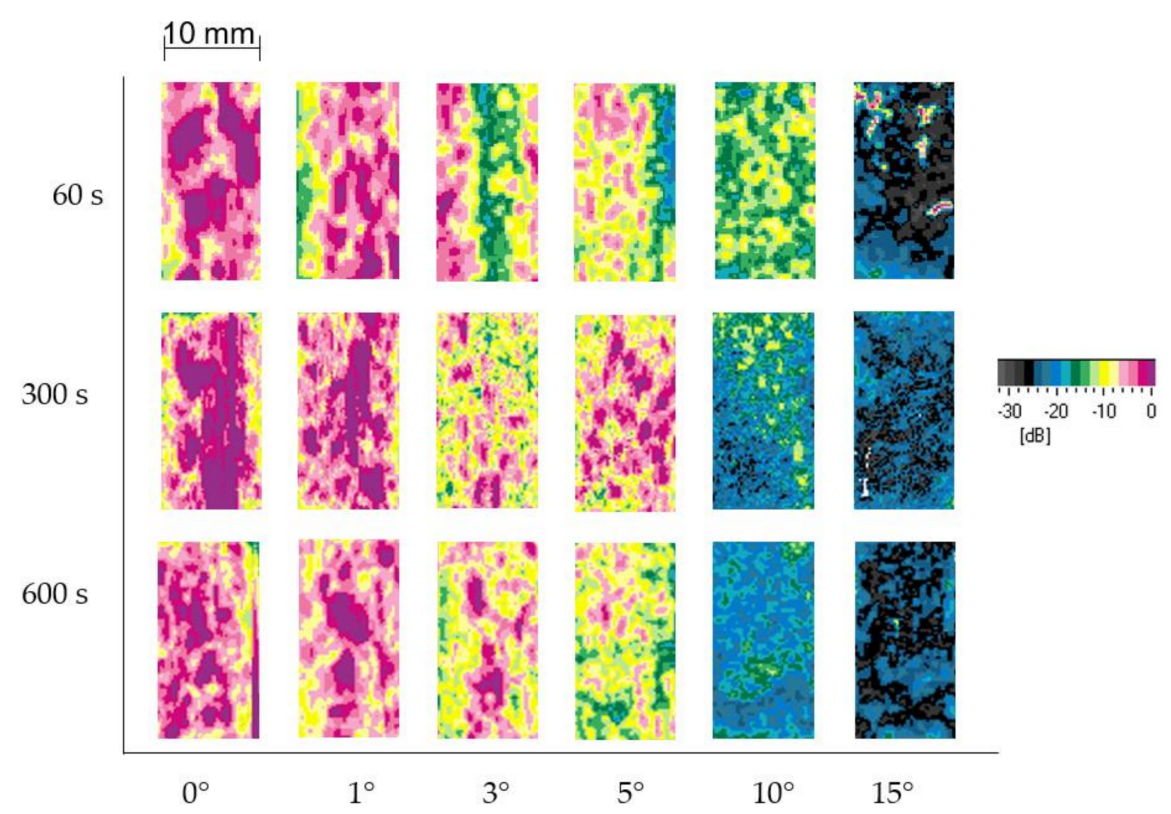

Figure 11. Ultrasonic C-scans from the back side of samples with various out-of-plane fibre angles after hot-air treatment for 60 to $600 \mathrm{~s}$.

Ultrasonic C-scans from the back side of the samples indicate intact material on the back side for low out-of-plane fibre angles $\left(0^{\circ}\right.$ and $\left.1^{\circ}\right)$. With increasing fibre angles, ultrasound is attenuated by deeper areas in the panel corresponding to a more pronounced decomposition of the matrix, which progresses from the front side to the back side of the samples with an increasing duration of hot-air treatment. Especially for the sample with an out-of-plane fibre orientation of $10^{\circ}$ treated for $300 \mathrm{~s}$, an inhomogeneous degradation can be observed on the back side. However, ultrasonic C-scans cannot significantly characterise matrix decomposition for this type of samples and are not ideal for measuring penetration depth compared to $\mu \mathrm{CT}$. $\mu \mathrm{CT}$ images indicate that cracks and delaminations completely penetrate all investigated samples. However, pronounced matrix decomposition and areas of resin-depleted fibres are limited and increase with higher out-of-plane fibre angles. For low fibre angles up to $5^{\circ}$, matrix decomposition is observed to penetrate the material more homogeneously and less deeply. Matrix decomposition is favoured to occur along the fibres, as indicated in the $\mathrm{xz}$ cross-sections, especially for out-of-plane fibre angles of $10^{\circ}$ and $15^{\circ}$. Areas at the edge of the samples, where fibres have no access to the hot surface, are less degraded. Here, adjacent fibres with access to the hot surface protect the matrix underneath, as heat is predominantly conducted along these fibres. Resin-depleted fibres act as a barrier for the heat transfer into the bulk material and for transport processes for decomposition products to the sample surface. However, these resin-depleted fibres with out-of-plane fibre angles between $3^{\circ}$ and $10^{\circ}$ are still locked in the resin matrix underneath, which can be seen by the additional white lines in Figure 12 representing the nominal out-of-plane angle.

In Figure 13, the maximum depths of resin-depleted areas are presented as being dependent on out-of-plane fibre angle after 60 and $300 \mathrm{~s}$ of thermal treatment. After $60 \mathrm{~s}$, $0.73 \mathrm{~mm}$ of the material without out-of-plane fibre orientation is penetrated, corresponding to an average decomposition velocity of $\sim 12 \mu \mathrm{m}$ per second perpendicular to the fibres. With increasing out-of-plane fibre angles, the penetration depth increases. With a nearly linear increase in the penetrated depth for fibre angles up to $15^{\circ}$, an additional contribution to this velocity by the out-of-plane fibre angle of roughly $1.5 \mu \mathrm{m}$ per second and angle degree is calculated (see linear regression in Figure 13: $0.088 \mathrm{~mm} / 60 \mathrm{~s}=1.47 \mu \mathrm{m} / \mathrm{s}$ ). Therefore, decomposition velocity in depth direction is $\sim 33 \mu \mathrm{m} / \mathrm{s}$ for the sample with an out-of-plane fibre orientation of $15^{\circ}$. For a hot-air treatment up to $300 \mathrm{~s}$, a penetration depth of $1.1 \mathrm{~mm}$ is observed, and an average decomposition velocity of $3.6 \mu \mathrm{m}$ per second 
is calculated for the material with a $0^{\circ}$ out-of-plane fibre orientation. An additional contribution to this velocity by the out-of-plane fibre angle is roughly $0.3 \mu \mathrm{m}$ per second and angle degree (see Figure 13: $0.088 \mathrm{~mm} / 300 \mathrm{~s}=0.29 \mu \mathrm{m} / \mathrm{s}$ ). Therefore, the sample with an out-of-plane fibre angle of $10^{\circ}$ is already completely penetrated.

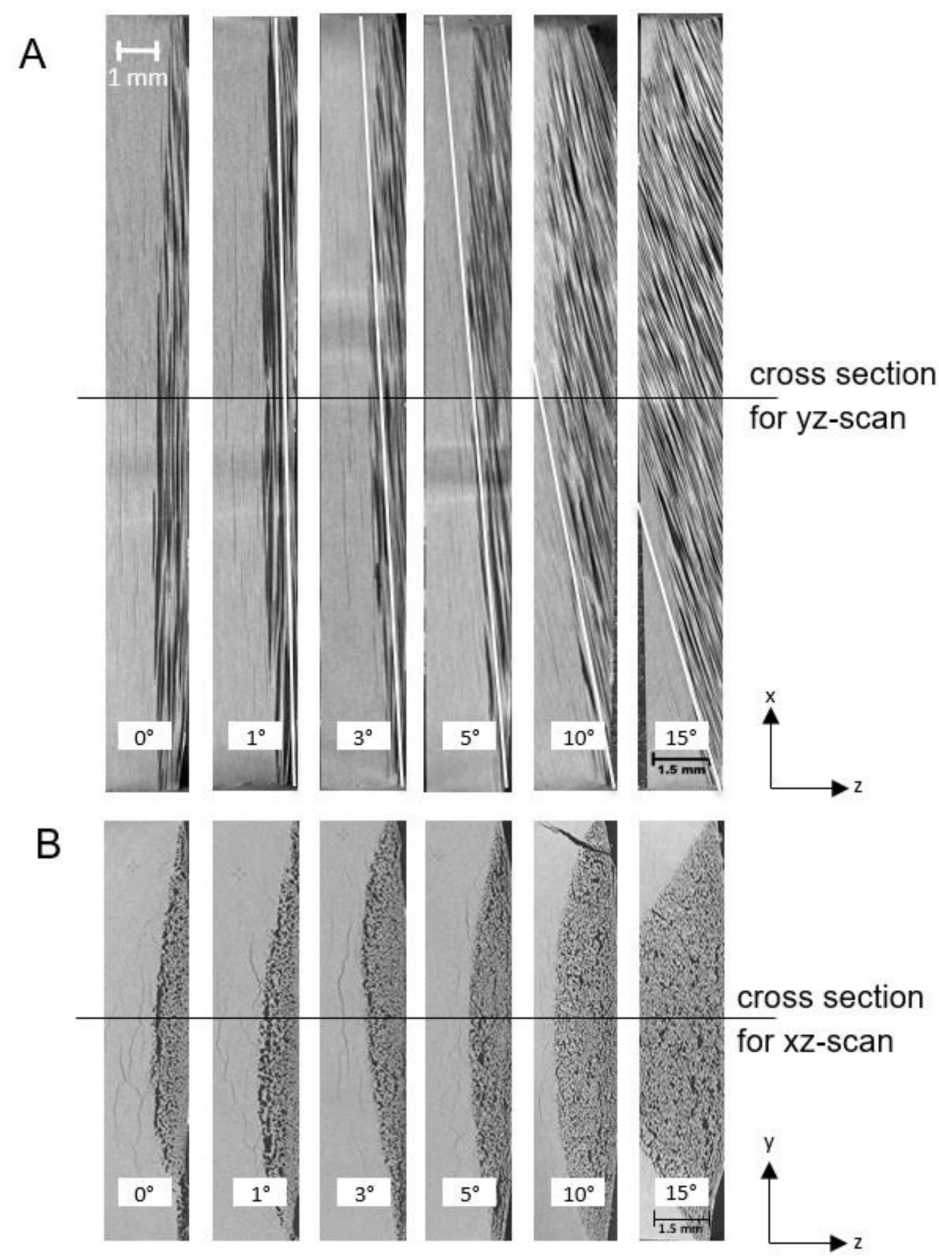

Figure 12. Microfocused computed X-ray tomography $(\mu \mathrm{CT})$ analysis of CFRP samples with outof-plane fibre orientation after $60 \mathrm{~s}$ of the hot-air treatment. (A): xz cross-section with indicated out-of-plane angle (white line); (B): yz cross-section.

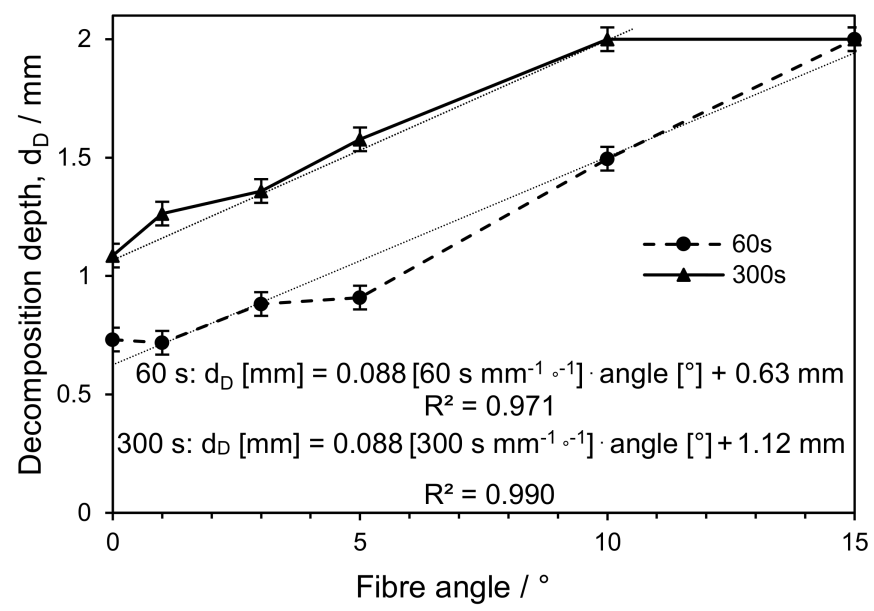

Figure 13. Maximum depth of matrix decomposition determined by $\mu \mathrm{CT}$ analysis (see Figure 9), and linear regressions for angle-dependent decomposition velocity (see text). 
The decomposition of the polymer matrix leads to the formation of a liquid. This liquid is observed at the sample surface. In Figure 14, the surfaces of the samples with various out-of-plane fibre angles are shown after $60 \mathrm{~s}$ of hot-air impact. For an out-of-plane angle of $0^{\circ}$, loose fibres are observed, which are easily removed from the surface. For an angle of $1^{\circ}$, a rough surface can still be found, but it has less loose fibres. With an angle of $3^{\circ}$, the surface is formed like scales and no more loose fibres are found. Beginning from $5^{\circ}$, traces of a condensed, solid pyrolysate of the matrix are observed. Corresponding to the increasing mass loss and the reduced barrier effects for high out-of-plane fibre angles of $10^{\circ}$ to $15^{\circ}$, the amount of condensed pyrolysate increases and a radial symmetric structure forms, which is caused by the impinging air.
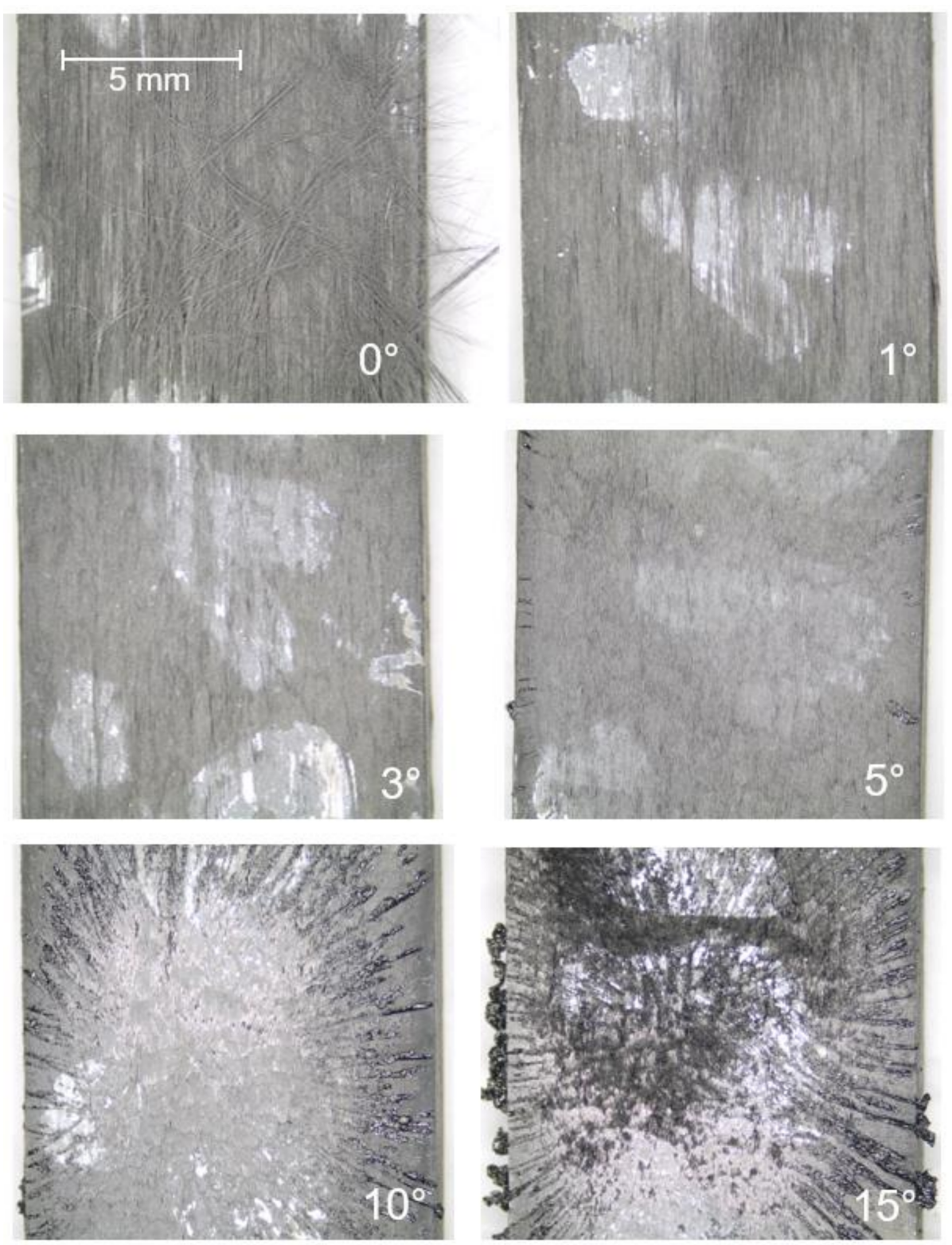

Figure 14. Images of the front side of samples with the given out-of-plane fibre angle after $60 \mathrm{~s}$ of the ablation experiment.

An SEM image of the surface of a $15^{\circ}$ sample treated for $60 \mathrm{~s}$ (Figure 15) also shows the condensed pyrolysate and additionally proves that carbon fibres are not decomposed after thermal loading with hot air. The scale-shaped surface is formed by areas of fibre endings held together by residual polymer and surrounded by large cracks penetrating the material along the fibres. This observation is different from 8552/IM7 material in 
irradiation experiments. In those experiments, the material ignites and combustion at higher temperatures forms loose char at the surface [25].
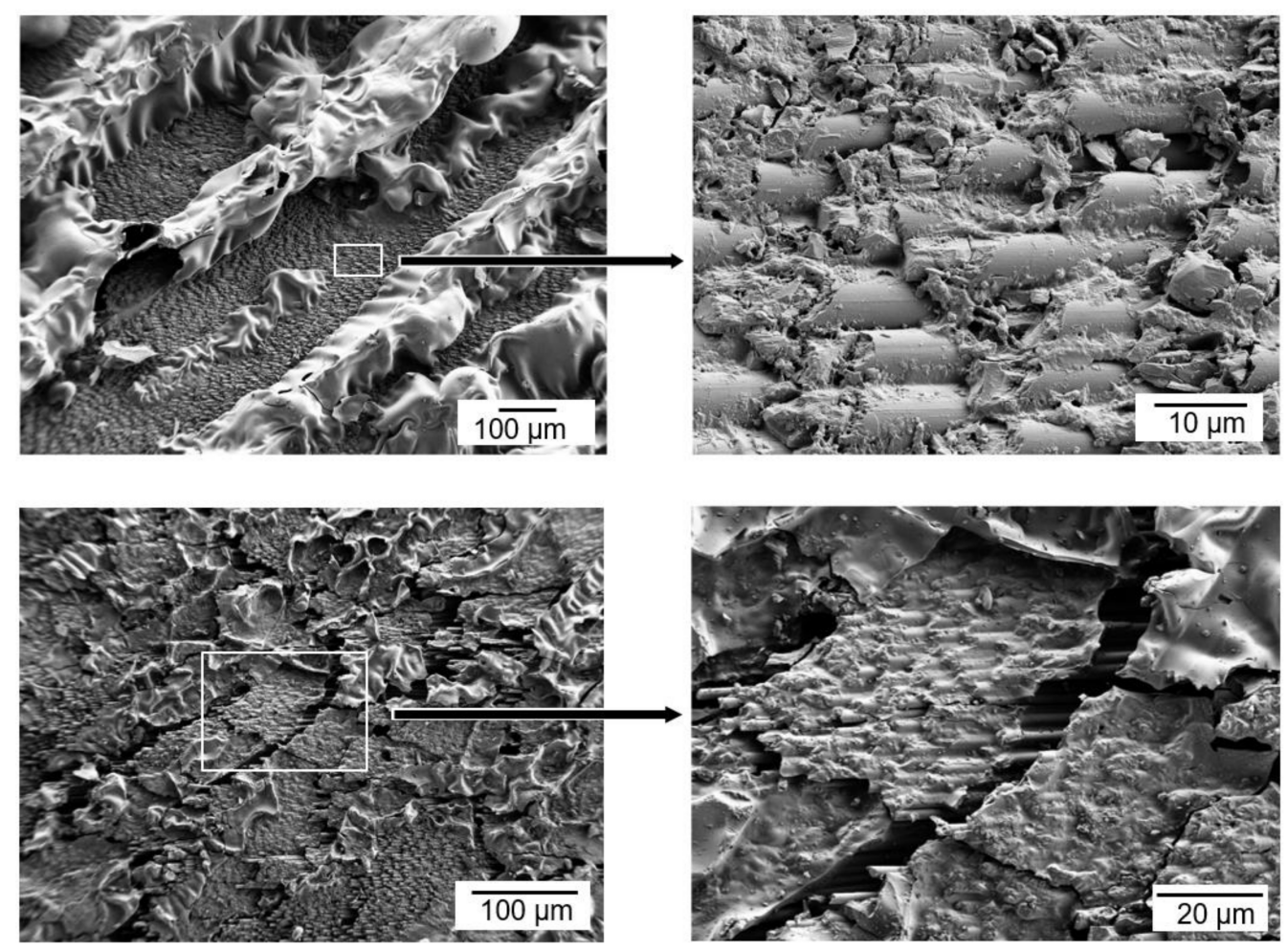

Figure 15. SEM photographs of the surface of a sample with an out-of-plane fibre angle of $15^{\circ}$ after $60 \mathrm{~s}$ of hot-air treatment.

In summary, due to the increased out-of-plane fibre angle, more heat is conducted from the hot surface into the bulk of the material, and decomposition products are more easily transported to the surface. Barrier effects by the fibre plies are reduced. These effects increase the overall decomposition of the polymer matrix.

Moderate polymer degradation can be measured by FTIR spectroscopy on the back side of the samples. Figure 16 shows results for the samples with different fibre angles. The obtained spectra are typical for the 8552/IM7. A detailed assignment of bands is given in [29]. Characteristic bands at 1510 and $1486 \mathrm{~cm}^{-1}$ are attributed to the epoxy resin and the polyethersulfone (PES), respectively [29]. A broad signal at $1650 \mathrm{~cm}^{-1}$ originates from carbonyle species in oxidation products. With an increasing out-of-plane fibre angle, the band at $1510 \mathrm{~cm}^{-1}$ loses intensity, which corresponds to a preferred degradation of the epoxy resin. As can also be seen in the thermogravimetric analysis, the epoxy resin in $8552 /$ IM7 is less thermally resistant than the polyethersulfone. Therefore, a lower ratio of the intensities of the signals at 1510 and $1486 \mathrm{~cm}^{-1}\left(\mathrm{I}_{1510 \mathrm{~cm}^{-1 /}} \mathrm{I}_{1486 \mathrm{~cm}^{-1}}\right)$ corresponds to a more pronounced thermal degradation [26]. In Figure 17, this intensity ratio is given for the three positions on the back side of samples with different out-of-plane fibre angles after different durations of hot-air treatment. With increasing time, the observed intensity ratios are, in general, lower, indicating the proceeding thermal degradation of the polymer. For increasing fibre angles, a more pronounced polymer degradation occurs corresponding to the higher measured back side temperatures (see Figure 8). As expected, the thermal degradation of the polymer is only slightly depending on the fibre angle at position 3 . At position 3, temperatures are lowest and least dependent on fibre angle. In contrast, at the other positions, matrix decomposition increases more strongly with an increasing fibre angle, as more heat is conducted to these areas on the back side of the samples. For example, after $60 \mathrm{~s}$ of thermal treatment, the samples with an out-of-plane angle beginning from $15^{\circ}$ show a complete decomposition of the epoxy resin at the center of the samples' 
back side (positions 1 and 2), whereas for the $10^{\circ}$ sample, resin remains. After $300 \mathrm{~s}$, the sample with a $10^{\circ}$ out-of-plane fibre angle also shows a complete decomposition of the matrix at the center of the back side. These observations correspond to the maximum depths of resin-depleted areas traced by $\mu \mathrm{CT}$ (Figure 12).

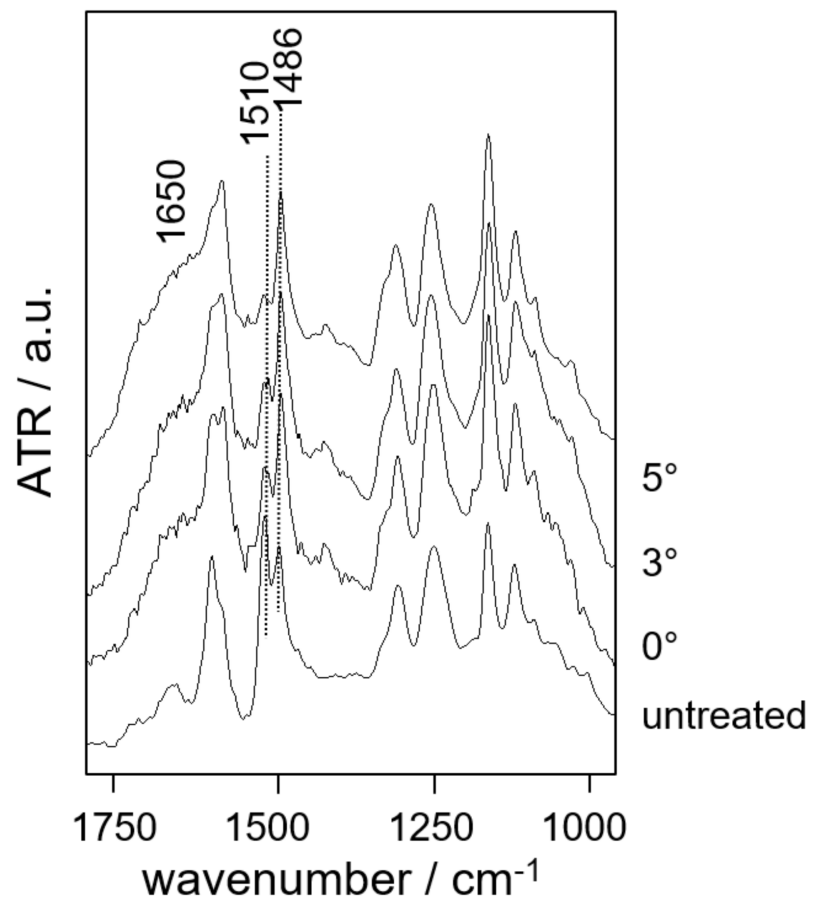

Figure 16. Infrared spectra ( $\mu$-ATR-FTIR) in the center of the samples' back side (position 2 in Figure 2) with a given out-of-plane fibre angle after $300 \mathrm{~s}$ of hot-air treatment.

\subsection{Residual Strength after Thermal Impact}

Thermally loaded samples are investigated for their residual short beam shear strength (SBSS). SBSS was chosen for mechanical testing, because the small area of thermal damage induced by the heat gun is best represented by the small samples ( $20 \mathrm{~mm} \times 10 \mathrm{~mm})$, and SBSS is less influenced by specimen geometry, for example, compared to the influence of the out-of-plane fibre angle on tensile strength (see above). Figure 18A presents the SBSS dependent on loading time. The drop in residual strength due to thermal loading is similar for samples with out-of-plane fibre angles between $0^{\circ}$ and $3^{\circ}$ within measurement tolerance. These samples lose one third of their initial SBSS after $600 \mathrm{~s}$, whereas samples with out-of-plane fibre angles higher than $5^{\circ}$ already completely degrade with respect to residual strength after $60 \mathrm{~s}$ of thermal treatment. An explicit comparison of residual strength is only possible for each fibre angle between various loading times (see Figure 18B), in order to not only consider the influence by the changing damage mechanism for various out-of-plane fibre angles. Within this comparison the relative decrease in SBSS is also similar up to an out-of-plane fibre angle of $3^{\circ}$. For angles higher than $3^{\circ}$, degradation is more pronounced with increasing angles. For $15^{\circ}$, residual strength is nearly completely lost after $60 \mathrm{~s}$. In other words, loading time shows a significant influence on the residual SBSS of samples with low out-of-plane fibre angles, whereas for high fibre angles degradation is faster, and loading time is less decisive for the chosen conditions. In principle, the loss of SBSS can be correlated to matrix decomposition. Therefore, a first insight is given by the $\mu \mathrm{CT}$ analysis presented in Figures 12 and 13. More precisely, for the less decomposed matrix, the degradation of the polymer at the samples' back side is correlated to residual SBSS in Figure 19 by means of infrared spectroscopy. In Figure 19, all samples are shown together with IR data representing position 1 on their back sides including all out-of-plane fibre angles and loading durations. Position 1 best represents back side conditions for a 
larger component and typically stands for the most pronounced degradation compared to positions 2 and 3 . With increasing matrix degradation, which corresponds to a decreasing

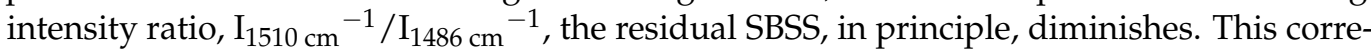
lation comprises the increasing degradation of the matrix with the duration of thermal load and increasing out-of-plane fibre angle (see shaded symbols in Figure 19). Both duration and out-of-plane fibre angle significantly influence matrix degradation and residual SBSS. The correlation can be, in principle, used to non-destructively estimate the residual SBSS of a component with out-of-plane fibre angles. By measuring infrared spectra at the samples' back side, an empirical prediction of mechanical performance can be achieved rapidly. However, standard deviations for the determined intensity ratios of the characteristic infrared bands are quite high, leading to not very precise estimations.

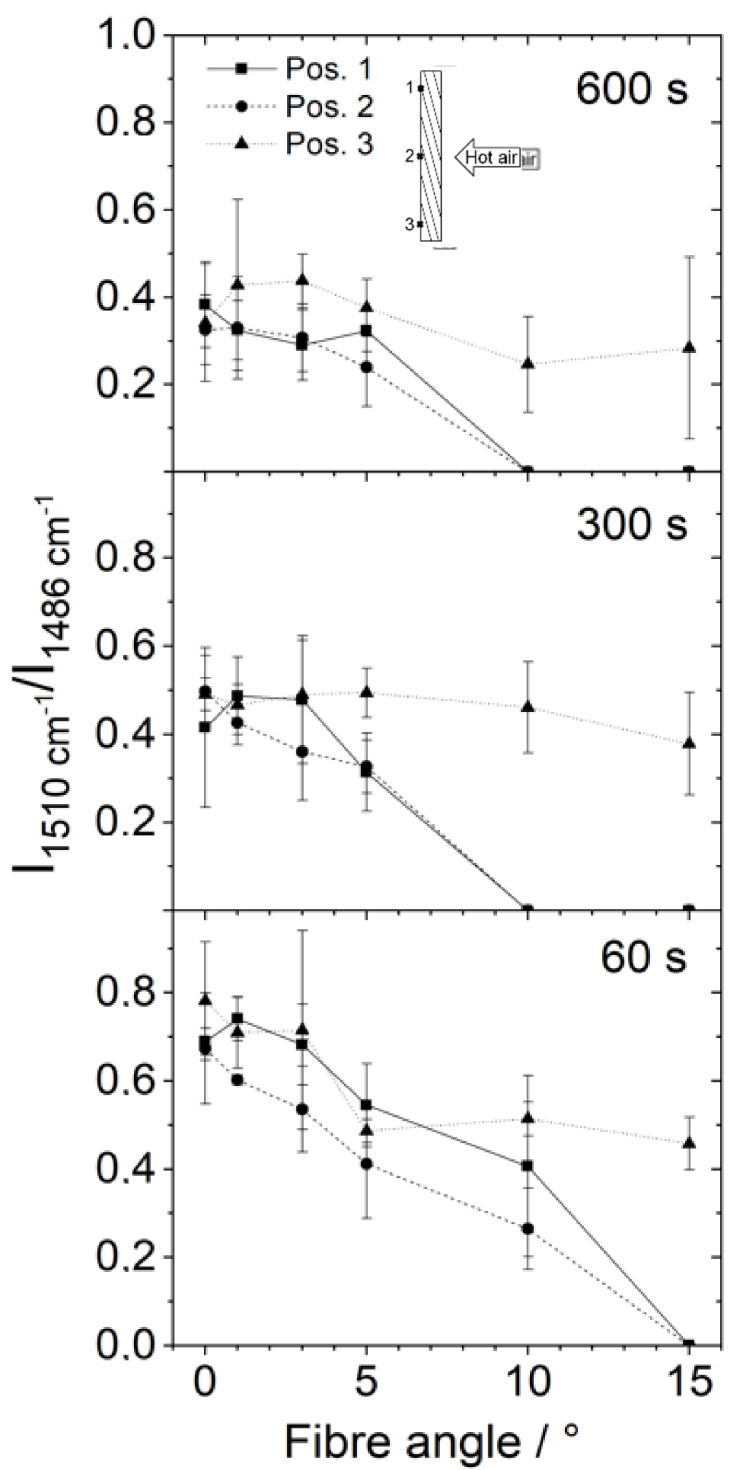

Figure 17. Intensity ratio of IR bands at $1510 \mathrm{~cm}^{-1}$ (EP) and $1486 \mathrm{~cm}^{-1}$ (PES) recorded at different positions on the back side of the samples after hot-air treatment for different times. 

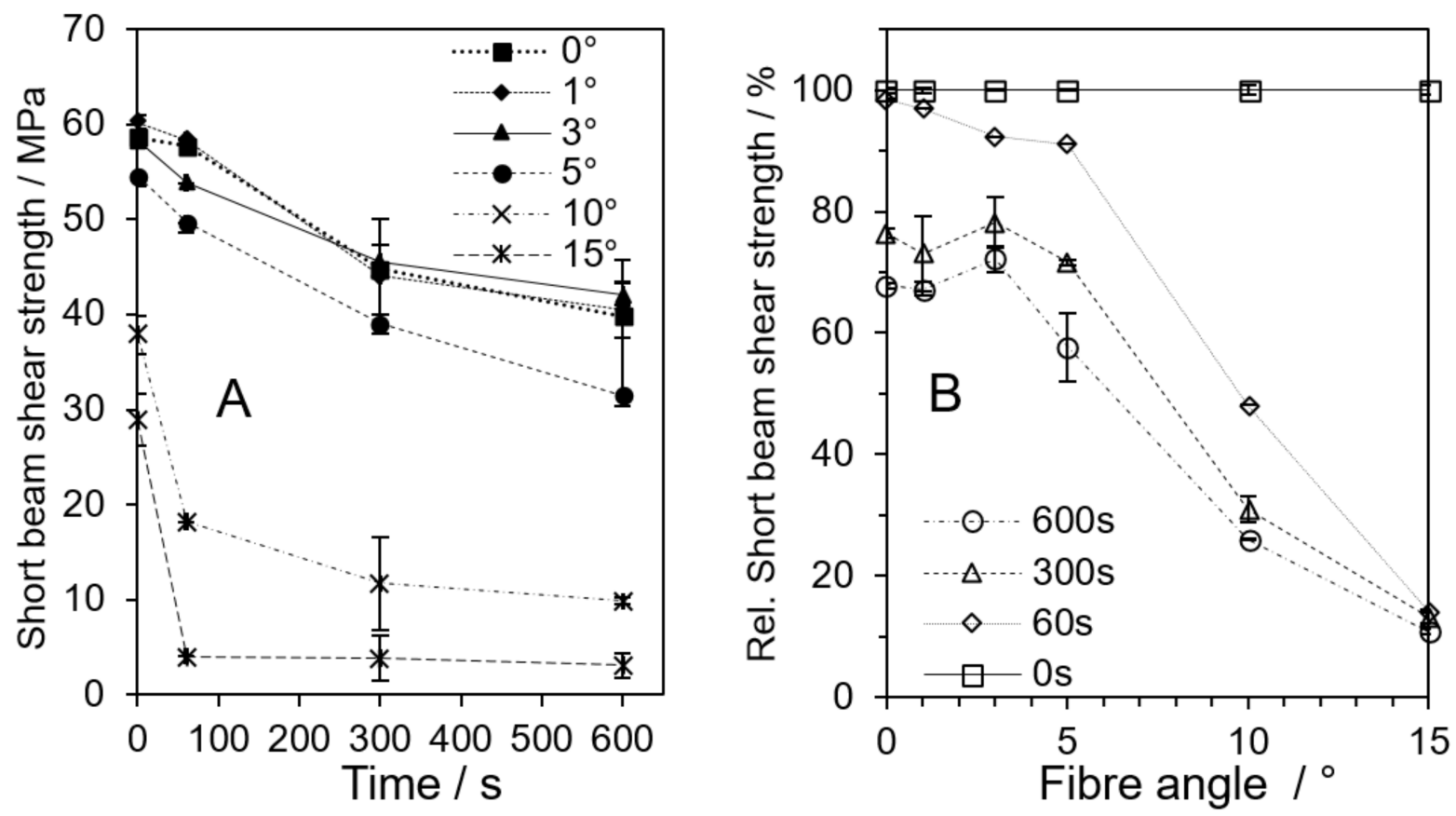

Figure 18. Short beam shear strength of samples after hot-air treatment. (A): dependent on loading time; (B): each sample related to the corresponding sample with the same out-of-plane fibre angle but without thermal treatment $(0 \mathrm{~s})$.

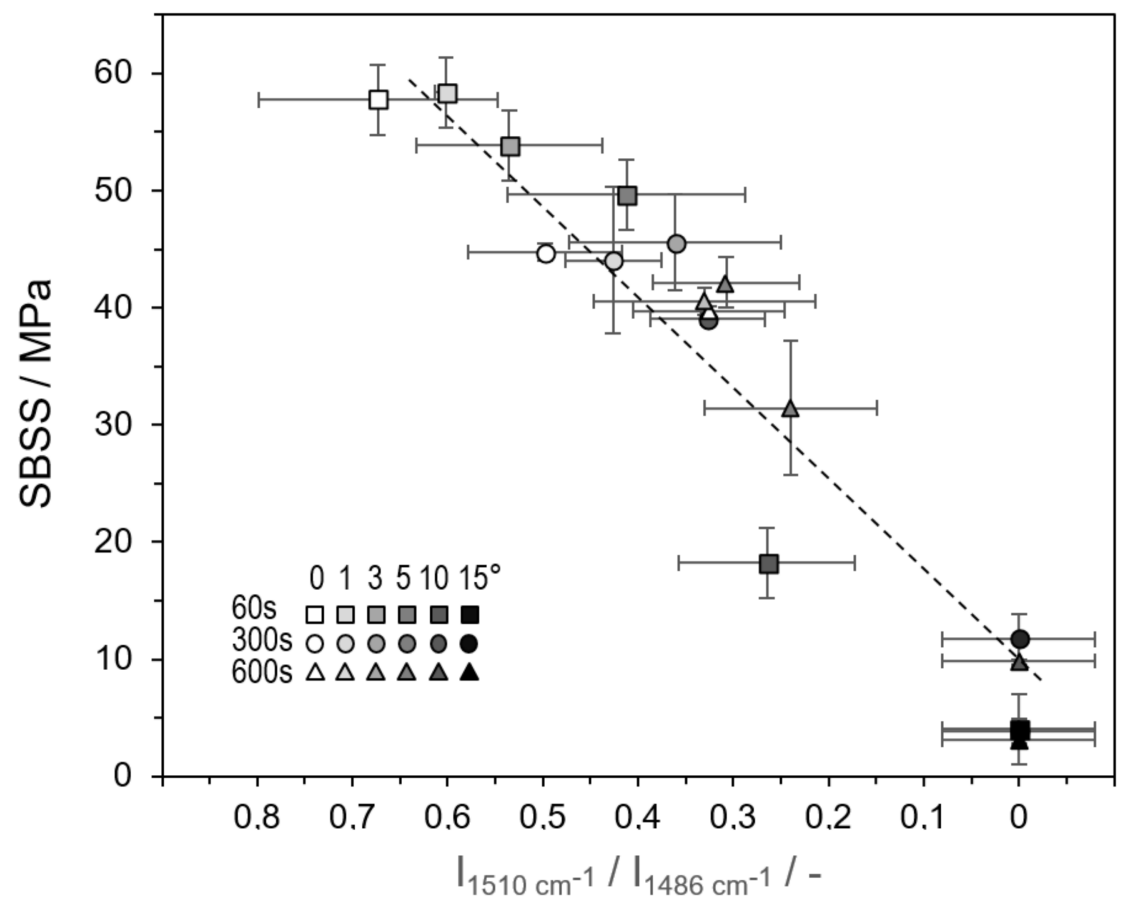

Figure 19. Correlation of short beam shear strength (SBSS) and matrix degradation by means of the intensity ratio of IR bands at $1510 \mathrm{~cm}^{-1}$ (EP) and $1486 \mathrm{~cm}^{-1}$ (PES) at position 1 on the back side of samples for all out-of-plane fibre angles and test durations. (The dashed line is introduced for clarity reasons only.)

\section{Conclusions}

This work assesses the potential use of CFRP with an out-of-plane fibre orientation for structural components under ablative conditions. Therefore, samples of an epoxybased CFRP with low out-of-plane fibres are examined using a hot-air blower. Achieved temperatures are high enough to decompose the matrix but not the fibres. Up to an out- 
of-plane fibre angle of $\sim 3^{\circ}$, a slight reduction in initial mechanical performance seems negligible for applications in structural components. The thermal conductivity through thickness of intact CFRP rises with an increasing out-of-plane fibre angle and penetration depth, as barrier effects for the migration of decomposed material by the fibres are reduced. However, resin-depleted fibres are fixed by the partially intact matrix material underneath, keeping them in position in a real ablative application.

Occurring temperature and measured residual strength can be well correlated to the observed matrix degradation characterised by infrared spectroscopy on the samples' back side. Therefore, infrared spectroscopy might also be used to rapidly predict residual strength for CFRP samples with an out-of-plane fibre orientation.

The conducted experiments in principle describe a successful way to apply out-ofplane fibre orientation for ablative materials. An out-of-plane fibre orientation of $\sim 3^{\circ}$ is identified as a good compromise between loss of strength and thermal conductivity as well as matrix degradation. It is expected that the observed effects are more pronounced in samples thicker than the used $2 \mathrm{~mm}$ samples. Additionally, matrices as well as fibres with higher thermal resistance are supposed to improve ablation performance. Matrices containing high-temperature-resistant polymers and reinforcements with non-combustible fibres seem especially interesting. A further way to use fibres with an out-of-plane orientation in ablative processes is to fix them in thermally resistant substrates and apply ablative layers, which are penetrated by the fibres. The fibres prevent the ablative layers from being easily removed. Matrix-depleted fibres with out-of-plane angles at the surface may additionally positively influence the laminar flow of air in high-speed applications.

Samples used for this investigation were complex to manufacture. It is far easier to apply winding techniques, for example, with a slight lateral offset of the applied prepreg layers to prepare CFRP pipes with an out-of-plane fibre orientation [28]. Obtained results may also apply for composites with partial out-of-plane fibre reinforcement, such as fabrics or braided structures.

The conducted experiments take a longer time compared to typical hypersonic applications of one-way parts with only several seconds. Therefore, the performance of fibre-reinforced composites with an out-of-plane fibre orientation might be sufficient to warrant their use as a structural lightweight material with improved ablation behaviour in the future.

Author Contributions: Conceptualization, S.E.; methodology, S.E., T.J.S. Schuster; validation, S.E., T.J.S. Schuster; formal analysis, S.E., T.J.S. Schuster; investigation, S.E., T.J.S. Schuster; resources, S.E., T.J.S. Schuster.; data curation, S.E., T.J.S. Schuster; writing—original draft preparation, S.E., T.J.S. Schuster; writing—review and editing, S.E.; visualization, S.E., T.J.S. Schuster; All authors have read and agreed to the published version of the manuscript.

Funding: This research received no external funding.

Institutional Review Board Statement: Not applicable.

Data Availability Statement: Data are available by request from S.E.

Conflicts of Interest: The authors declare no conflict of interest.

\section{References}

1. Wolfrum, J.; Eibl, S.; Lietch, L. Rapid evaluation of long-term thermal degradation of carbon fibre epoxy composites. Compos. Sci. Technol. 2009, 69, 523-530. [CrossRef]

2. Toldy, A.; Szolnoki, B.; Marosi, G. Flame retardancy of fibre-reinforced epoxy resin composites for aerospace applications. Polym. Degrad. Stab. 2011, 96, 371-376. [CrossRef]

3. Scudamore, M.J. Fire performance studies on glass-reinforced plastic laminates. Fire Mater. 1994, 18, 313-325. [CrossRef]

4. Perret, B.; Schartel, B.; Stöß, K.; Ciesielski, M.; Diederichs, J.; Döring, M.; Krämer, J.; Altstädt, V. Novel DOPO-based flame retardants in high-performance carbon fibre epoxy composites for aviation. Eur. Polym. J. 2011, 47, 1081-1089. [CrossRef]

5. Perez, R.M.; Sandler, J.K.W.; Altstädt, V.; Hoffmann, T.; Pospiech, D.; Ciesielski, M.; Döring, M.; Braun, M.; Knoll, U.; Schartel, B. Effective halogen-free flame retardants for carbon fibre-reinforced epoxy composites. J. Mater. Sci. 2006, 41, 4981-4984. [CrossRef] 
6. Braun, U.; Schartel, B.; Fichera, M.A.; Jäger, C. Flame retardancy mechanisms of aluminum phosphinate in combination with melamine polyphosphate and zinc borate in glass-fibre reinforced polyamide 6,6. Polym. Degrad. Stab. 2007, 92, 1528-1545. [CrossRef]

7. Greiner, L.; Döring, M.; Eibl, S. Prevention of the formation of respirable fibers in carbon fiber reinforced epoxy resins during combustion by phosphorus or silicon containing flame retardants. Polym. Degrad. Stab. 2021, 185, 109497. [CrossRef]

8. Schuster, T.J.; Weller, L.; Wolfrum, J.; Eibl, S. Silver nanoparticle modified carbon fiber-reinforced polymer material for resistance against thermal damage induced by irradiation. J. Compos. Mater. 2020, 55, 1267-1278. [CrossRef]

9. Lee, Y.; Joo, H.J. Investigation on ablation behavior of CFRP composites prepared at different pressure. Compos. Part A 2004, 35, 1285-1290. [CrossRef]

10. Cho, D.; Il Yoon, B. Microstructural interpretation of the effect of various matrices on the ablation properties of carbon-fibrereinforced composites. Compos. Sci. Technol. 2001, 61, 271-280. [CrossRef]

11. Chen, Y.; Milos, F.S. Ablation and Thermal Response Program for Spacecraft Heatshield Analysis. J. Spacecr. Rocket. 1999, 36, 475-483. [CrossRef]

12. Schmidt, D.L.; Schwartz, H.S. Evaluation methods for ablative plastics. SPE Trans. 1963, 3, 238-250.

13. Milos, F.S.; Chen, Y.; Congdon, W.M.; Thornton, J.M. Mars pathfinder entry temperature data, aerothermal heating, and heatshield material response. J. Spacecr. Rocket. 1999, 36, 380-391. [CrossRef]

14. Milos, F.S.; Chen, Y.; Squire, T.H.; Brewer, R.A. Analysis of galileo probe heatshield ablation and temperature data. J. Spacecr. Rocket. 1999, 36, 298-306. [CrossRef]

15. Bahramian, A.R.; Kokabi, M.; Famili Mohammad Hossein Navid Beheshty, M.H. Ablation and thermal degradation behaviour of a composite based on resol type phenolic resin: Process modeling and experimental. Polymer 2006, 47, 3661-3673. [CrossRef]

16. Ogasawara, T.; Ishikawa, T.; Yamada, T.; Yokota, R.; Itoh, M.; Nogi, S. Thermal Response and Ablation Characteristics of Carbon Fibre Reinforced Composite with Novel Silicon Containing Polymer MSP. J. Compos. Mater. 2002, 36, 143-157. [CrossRef]

17. ASTM E458-08 (2020). Standard Test Method for Heat of Ablation; ASTM International: West Conshohocken, PA, USA, 2020.

18. Torre, L.; Kenny, J.M.; Maffezzoli, A.M. Degradation behaviour of a composite material for thermal protection systems Part I-Experimental characterization. J. Mater. Sci. 1998, 33, 3137-3143. [CrossRef]

19. Gojny, F.H.; Wichmann, M.H.; Fiedler, B.; Kinloch, I.A.; Bauhofer, A.; Windle, A.H.; Schulte, K. Evaluation and identification of electrical and thermal conduction mechanisms in carbon nanotube/epoxy composites. Polymer 2006, 47, 2036-2045. [CrossRef]

20. Gojny, F.H.; Wichmann, M.H.; Fiedler, B.; Bauhofer, W.; Schulte, K. Influence of nano-modification on the mechanical and electrical properties of conventional fibre-reinforced composites. Compos. Part A Appl. Sci. Manuf. 2005, 36, 1525-1535. [CrossRef]

21. Schuster, T.; Eibl, S.; Gudladt, H.-J. Influence of carbon nanotubes on thermal response and reaction to fire properties of carbon fibre-reinforced plastic material. J. Compos. Mater. 2018, 52, 567-579. [CrossRef]

22. Park, J.-M.; Kwon, D.-J.; Wang, Z.-J.; Roh, J.-U.; Lee, W.-I.; Park, J.-K.; DeVries, K.L. Effects of carbon nanotubes and carbon fibre reinforcements on thermal conductivity and ablation properties of carbon/phenolic composites. Compos. Part B Eng. 2014, 67, 22-29. [CrossRef]

23. Pötschke, P.; Fornes, T.D.; Paul, D.R. Rheological behavior of multiwalled carbon nanotube/polycarbonate composites. Polymer 2002, 43, 3247-3255. [CrossRef]

24. Song, Y.S.; Youn, J.R. Influence of dispersion states of carbon nanotubes on physical properties of epoxy nanocomposites. Carbon 2005, 43, 1378-1385. [CrossRef]

25. Eibl, S. Influence of carbon fibre orientation on reaction-to-fire properties of polymer matrix composites. Fire Mater. 2012, 36, 309-324. [CrossRef]

26. Eibl, S.; Swanson, D. Influence of out-of-plane fibre orientation on reaction-to-fire properties of carbon fibre reinforced polymer matrix composites. Fire Mater. 2018, 42, 234-243. [CrossRef]

27. ASTM E285-08. Standard Test Method for Oxyacetylene Ablation Testing of Thermal Insulation Materials; ASTM International: West Conshohocken, PA, USA, 2020.

28. Eibl, S. Method for Producing a Pipe Section of a Missile Outer Shell and Pipe Section of a Missile Outer. Shell. Patent DE102017007059, 1 April 2021.

29. Eibl, S. Observing Inhomogeneity of plastic components in carbon fibre reinforced polymer materials by ATR-FTIR spectroscopy in the micrometer scale. J. Compos. Mater. 2008, 42, 1231-1246. [CrossRef]

30. Hexcel Corporation. HexPly 8552 Epoxy Matrix Product Data Sheet; Hexcel Corporation: Stamford, CT, USA, 2013.

31. ISO 5660. Reaction-to-Fire Tests-Heat Release, Smoke Production and Mass Loss Rate-Part 1: Heat Release Rate (Cone Calorimeter Method) and Smoke Production Rate (Dynamic Measurement); Beuth Verlag GmbH: Berlin, Germany, 2015.

32. DIN EN ISO 527-5. Plastics_Determination of Tensile Properties-Part 5: Test Conditions for Unidirectional Fibre-Reinforced Plastic Composites; Beuth Verlag GmbH: Berlin, Germany, 2010.

33. DIN EN ISO 14126. Fibre-Reinforced Plastic Composites-Determination of Compressive Properties in the In-Plane Direction; Beuth Verlag GmbH: Berlin, Germany, 2000.

34. DIN EN 2563. Aerospace Series-Carbon Fibre Reinforced Plastics-Unidirectional Laminates; Determination of Apparent Interlaminar Shear Strength; Beuth Verlag GmbH: Berlin, Germany, 1997.

35. DIN EN 22007-4. Plastics—Determination of Thermal Conductivity and Thermal Diffusivity—Part 4: Laser Flash Method; Beuth Verlag GmbH: Berlin, Germany, 2008. 
36. DIN 53765 F. Testing of Plastics and Elastomers; Thermal Analysis of Polymers; DSC-method; Beuth Verlag GmbH: Berlin, Germany, 1994.

37. DIN EN ISO 845. Determination of Apparent Bulk Density, Cellular Plastics and Rubbers; Beuth Verlag GmbH: Berlin, Germany, 1995.

38. Zoghi, M. The International Handbook of FRP Composites in Civil Engineering; CRC Press, Taylor \& Francis: Boca Raton, FL, USA, 2014.

39. Vetter, T.M.; Bibinger, J.; Zimmer, F.; Eibl, S.; Gudladt, H.J. Characterization of one-sided thermal damage of carbon fiber reinforced polymers by means of depth profiles. J. Compos. Mater. 2020, 54, 3699-3713. [CrossRef]

40. Hexcel Corporation. HexTow IM7 Carbon Fibre Product Data Sheet; Hexcel Corporation: Stamford, CT, USA, 2016.

41. Hasselman, D.P.H.; Bhatt, H.; Donaldson, K.Y.; Thomas, J.R. Effect of fibre orientation and sample geometry on the effective thermal conductivity of a uniaxial carbon fibre-reinforced glass matrix composite. J. Compos. Mater. 1992, 26, 2278-2288. [CrossRef]

42. Schartel, B.; Hull, T.R. Development of Fire-Retarded Materials-Interpretation of Cone Calorimeter Data. Fire Mater. 2007, 31, 327-354. [CrossRef]

43. Eibl, S. Potential for the formation of respirable fibres in carbon fibre reinforced plastic materials after combustion. Fire Mater. 2017, 41, 808-816. [CrossRef]

44. Wolfrum, J.; Whitney, E.; Eibl, S. Approaches to understand and predict the influence of rapid heat-up on degradation and strength of carbon fibre polymer matrix composites. J. Compos. Mater. 2017, 51, 2435-2447. [CrossRef] 